This is an Author Accepted Manuscript (AAM) for the journal Critical Studies on Security (accepted 31/08/2018)

Please cite from: https://doi.org/10.1080/21624887.2018.1522103

Aishling McMorrow, University of Portsmouth

\title{
Layers of Affect: The Liminal Sites of Method
}

\begin{abstract}
Recent moves to (re)incorporate the registers of affect and emotion into the discipline of International Relations have been spearheaded within the study of security. Across airports, borders, and urban spaces, we have seen the lines of control by which certain affects and emotions are orientated and manipulated, in order to (dis)aggregate and discipline bodies. However, while there is a concerted effort to imagine and foreground theoretically how bodies have the dual capacity to affect and to be affected, thus, playing back into forms of control, a clear delineation on method is, so far, absent. In other words, how exactly can we juggle uncovering the ways in which affect and emotion are always simultaneously obedient and deviant? Therefore, this article will set out a methodological framework that enables research to stay attuned to, and cognisant of, the competing layers of these registers that both play into and rupture mechanisms of control in security. I argue that imagining fieldwork and research on affect and emotion as liminal sites, through three layers, allows for the translation of the control of and by affect, while simultaneously embracing the liveliness, disruption, and tensions that affect and emotion create.
\end{abstract}

Keywords: affect, emotion, bodies, method, liminal. 


\section{Introduction}

Drawing inspiration from critical geography (Adey 2008, Anderson and Adey 2011, Thrift 2004), the affective turn in politics (Thompson \& Hoggett 2012) and the call for the greater incorporation of emotions into International Relations (Bleiker and Hutchinson 2008, Hutchinson and Bleiker 2014) has spurred a range of interesting insights into how our political landscape is shaped by the registers of affect and emotion. At the forefront of this effort sits the study of security, broadly, which has succinctly recognised the registers that 'not only represent a particular feeling or sensibility but also actively shape the world around us and the bodies that populate it' (Åhäll and Gregory 2013, 117; Hutchinson 2013). From this, security discourses, mechanisms, and practices have all been placed as inherently reliant on the registers of affect and emotion. The types of interventions that have been made assert that affect has been used as a method of control in measures at borders (Salter 2007, 2008, 2012) and the role of 'panic' in increasing securitisation (Salter and Mutlu 2012). Additionally, Amoore (2006) demonstrates that bodies will always exceed these attempts at regulation and calculation and, leading from this, how the possibility for 'alternative politics of border security' (Amoore and Hall 2010, 306; Amoore and Hall 2009) can be imagined and realised through affect.

Therefore, affect has also been presented as integral to upsetting and formulating resistance to dominant discourses and representations of security and terrorism. For example, Heath-Kelly and Jarvis (2017) recognise the affective drives that underpin the contemporary fascination with terrorism. Van Ramshorst (2017) identifies how affect and emotion add another dimension to our understanding of international migration, whereby migrants deal with brutality and violence through laughter and play. Finally, Innes (2017) calls attention to how our identity and our ontological security are constituted through everyday practices that are underpinned by affect and emotion. 
All of these efforts combined have made a significant impact in making us aware of the political importance of how affect imposes upon, mobilises, orientates, and controls bodies, specifically in the security context. However, while studies of security have started to pick apart how bodies are affected (Salter 2007, 2008), but not always successfully controlled (Amoore 2006), through and by security measures, we now need to think through how the corporeal can physically play back into these structures of control, through the interplay of affect and emotion. In other words, how there are multiple layers of affects and emotions that are all influential at spaces of (in)security, as just one example. The importance and significance of outlining a way to think through these layers is, as outlined by Åhäll (2018, 38 emphasis in original), to attempt to grasp the 'political effects of emotional practices.' Thus, the method that I present allows research to foreground the complexity of affect, emotion, and the corporeal in these landscapes, in order to contest reductive accounts of these spaces and security practices, and the bodies within them, as simply constructed and governed by fear and (in)security. By presenting a method that enables the revelation of a myriad of affects and emotions at these spaces, this article helps future research to challenge reductive accounts of fully controlled and predictable affects and emotions. In order to do so, this article shall, firstly, outline a conceptualisation of how the corporeal interacts with flows of affect (Ahmed 2003, 2004). Secondly and linked to this, the article will present a methodological framework that allows for the study of affect and emotion broadly, and the identification of how these registers enable bodies to be simultaneously obedient and deviant to contemporary security practices and mechanisms. I argue that these conversations and theorisations of affect are often absent as they raise undeniable challenges to method (Adey et al 2013). The theoretical framework certainly exists to imagine how affect and emotion can influence security measures, and even disrupt them. But the difficulty, and the gap that I want 
to address is, how we accommodate and thread the multiple layers of these registers through our fieldwork and research.

To address these absences and difficulties, this article will take the following shape. The first section will deal with the theoretical relationship between affect, emotion, and the corporeal, arguing that emotion, as one potential expression, is the physical (re)performance of affect.

Once the theoretical framework has been established, I will look at some of the challenges to transposing this relationship to fieldwork and research and the ways in which we can think past these obstacles. From this, I put forward the main intervention of the article which is to start to envision our fieldwork and research as liminal sites where we embrace ambiguity and disorientation, rather than shying away from it. Within these liminal sites, then, we need to approach affect, emotion, and the corporeal as layers rather than in a linear fashion of only control and obedience. What this enables is the ability to juggle a multitude of cohering, competing, and eruptive information and insights that is reflective of the nature of affect and emotion. Finally, I will tie in what could be seen as challenges to this method to a wider effort in social sciences to accept and get comfortable with dissonance and disruption.

\section{The Physical Relationship of Affect and Emotion}

\section{Affect}

Positioning emotion as the physical (re)performance of affect ${ }^{1}$ that can be traced through the corporeal, leads to interesting questions regarding what this physicality allows emotion to do on and through the body, and how we can identify or trace the physicality of this relationship at spaces of (in)security. Additionally, it also raises questions of how exactly we can track the

\footnotetext{
${ }^{1}$ As just one relationship that can be drawn from the pair.
} 
feedback loop of the corporeal into affect and emotion. Most immediately, though, this conceptualisation of affect and emotion calls for the classification of these two distinct but related registers, and how they feed into each other.

Firstly, in terms of affect, this register has evoked many divergent conceptualisations of its capabilities, characteristics and functions. However, there is a popular consensus, which I align to, whereby affect is asserted as something physical and tangible (Clough 2010; Clough and Halley 2007; Lorimer 2008; Massumi 2002). This physicality and its relation to the corporeal, then, is defined succinctly by both Deleuze (1988) and Negri (1999) as the power to act. Thus, my positioning of affect links to Massumi (2002), and is an intensity that exists within the body and escapes the constraints of a socially constructed label. From this, then, affect is pre-linguistic - which is distinctly different from emotion - and within this definition, it must be noted that the translation from affect to the body of the capability to act, the capability of movement and sensation, always occurs before it is identified through language. As such, affect is evident in and through the body by its very physicality; it is not something that we can articulate, but it is something that we can act out or perform. However, while Massumi positions affect in the realm of the virtual and potential, and subsequently argues that affect is pre-discursive, I radically differ on this point. Although, affect is prelinguistic, it cannot assume to be pre-discursive as, even in the realm of the potential movement of the body, where bodies are capable of moving, allowed to move, and what forms these movements take are all dependent on, and informed by, socially constructed boundaries and norms.

Linking back to the physical acting out or performance of affect is Spinoza's (1985) delineation of the dual capabilities of affect. This dual capacity means that bodies have the simultaneous ability to produce affect and also to be affected; exemplified in Wetherell's (2012) idea of 'affective practice' and shown in the power of affect to racialize bodies (Ngai 
2002). Thus, affect both emerges from and works upon the corporeal, all in flows with other bodies. In this manner, affect will always supersede attempts at control as engineered affects must always contend with bodies constantly feeding into and informing the affective landscape. Consequently, security measures and practices that function through the belief of the ability to control affect and emotion, have an inherently flawed understandings of the very registers that they are reliant on. Closs Stephens $(2016,184)$ best points to the diffuse and uncontrollable nature of affect, when she notes that during the London 2012 Olympics, 'feelings weren't simply orchestrated from the top-down but rather skipped between different sites and moments.' Crucially, this idea of the 'skipping flow' of affect points to how this register does not behave in a controlled and obedient manner, rather the flow of this register underscores the unpredictability and uncontrollability that defines affect.

From this, bodies are not mere receptacles within which emotions are housed, they are (inter)active and influential through their relation(s) with affect. Even when or where bodies are subjected to and must (re)perform set affects, there is always counter-conduct or deviance at play, which points to different affective resonances and the possibilities of different physical experiences. As power relations are not only inscribed upon the body, they are also (re)produced through these very same bodies (Butler 1989; Butler 1990), my synthesis of affect in this article, is to show that it is the dual capacity of bodies to affect and to be affected that constitutes, orders, and troubles these power relations. As such, the multitude of experiences of affect and emotion, especially at spaces of (in)security, are enabled by the dual capacity of bodies to affect and to be affected, which necessitates distinguishing the input of the body back into these affective flows.

The consideration of the ability of bodies to enact varying affective experiences, both obedient and deviant, and how these instances of affect are physical on and through the corporeal is thus necessary to broaden our understanding of affect. Additionally, this broader 
theoretical understanding will help us wade through the myriad of ways that affect and emotion (re)create different layers of experiences. Overall, then, it is clear that we need to appreciate that 'affect necessarily exceeds its capture and engineering' (Bissell, Hynes and Sharpe 2012,694) and can trouble and disrupt attempts at control. As such, even at sites of overwhelming affective control, like airports and border crossings, there are still interruptions of affective resistance where there is troubling and (re)ordering by bodies. This capability of affect to interrupt and deviate from control is exemplified by Adey $(2008,2009)$ who shows an acute awareness of the routine practices that are equally restrictive of and formed by the corporeal. As one example, at the airport, $\operatorname{Adey}(2008,439)$ intonates that 'the affective expression of hope, fear, joy, sadness, and many others, as well as the constitutive mundane bodily motions that occupy the airport terminal, may not be as distanced from power and control as we might think.' Rather than effacing the role of the body or disregarding the sometimes banal contribution of affects that are active, Adey is attuned to the fact that the corporeal, via the affective register, actually can physically (re)assemble forms of political control. Thus, through his work, Adey also adheres to a framework that permits the imagining of the political as constituted by multiple layers of affect and emotion, and the role that the body occupies in this.

\section{Emotion}

Taking all of these features of affect - physicality, dual capabilities, and the uncontrollability of affect - together, leads me to the relation of this register to emotion. I argue that affect and emotion are related but distinct entities, which is supported by both Massumi (1995) and Deleuze (1997). Again, Massumi (1995) exemplifies this separation in the 'autonomy of affect,' which represents the manner in which affect and emotion (inter)play with, and 
influence, the other and facilitates an understanding of the dividing lines between these two registers. The autonomy of affect, then, is the limit of affect or the point of emergence whereby the physicality of affect is realised through its expression in other registers. As Massumi (1995, 96) states, 'formed, qualified, situated perceptions and cognitions fulfilling functions of actual connection or blockage are the capture and closure of affect. Emotion is the intensest (most contracted) expression of that capture.' Thus, the limit of affect represents both an escape and a capture. It is the escape of the affective, as affect is transformed into emotion (as one potential result) and simultaneously it is the capture of the affective's potential to act in this qualified, outward expression of emotion. From this, I focus on the emotive, as one emergence of affect, which is imbued with all the characteristics of affect and the ability to express them on and through the body. As such, taking the relation of affect and emotion as theorised by Massumi, allows me to chart how affect is physically expressed and manifest through emotion, as one potential ${ }^{2}$ outward expression on the corporeal.

My conceptualisation of emotion as physical is also backed up by James $(1884,189-190)$ who establishes that 'the bodily changes follow directly the perception of the exciting fact, and that our feeling of the same changes as they occur is the emotion.' Therefore, drawing these two formulations of emotions together, I clarify that emotion is the physical (re)performance of affect. Although, I do differ from James who believes that only certain emotions are triggered by bodily reactions and others have "no obvious bodily expression for their consequence' (James 1884, 189). Contrary to this, I assert that emotions such as disinterest and displeasure still effect important changes and elicit dispositions that can be traced in and across the physical body. This recognition, then helps to theorise the importance

\footnotetext{
${ }^{2}$ It is important to note here, though, that the emotive as physical is just one rendering of the capabilities of emotions. As such, I completely agree that emotions, among many other features, are also beliefs and complex judgements (Nussbaum 2001), and are both influenced by and influential through language (Lutz and AbuLughod 1990). However, the purpose of this article is to focus on and trace the physical link to affect.
} 
of emotions and how, as the physical (re)performance of affect, they can help identify the flow of affect from and through bodies.

Theoretically, the importance of delineating this relationship is clear and enables us to envision how affect and emotion are (inter)active, and the ways in which they are simultaneously shaping of and shaped by the corporeal. However, the challenge that inherently comes from positioning emotion as the physical (re)performance of affect is how do we identify, trace, and tap into this physicality? If affect is a physicality that simultaneously plays upon and comes from the body, although we have ascertained its link to and reliance on emotion, how do we transpose this theoretical relationship into fieldwork and research? Furthermore, how do we immerse ourselves in this physical relationship as we are bodies that already experience and feed into a miasma of affects and emotions? At spaces of (in)security, under mechanisms of control and governance, how can we disentangle ourselves from the cultural and political scripts, and power structures, in order to critique their reductive use, and reliance on, affect and emotion? I believe that as the central criteria to link affect and emotion is physicality, then we need to create a way to engage with this physicality and to be attentive to affect, emotion, and the corporeal. Specifically, this is a challenge to method, where we need to attune ourselves to registers that are inherently ambiguous, amorphous, and tricky to define. Equally, there is also the inherent juxtaposition, if not paradox, of taking affect as a physical entity that escapes the confines of language and then seeking to do just that: trap it on a page. As pointed out by Adey et al $(2013,308)$, when studying affect we run into the challenge regarding 'how to write and/or represent such ambiances and atmospheres.' Therefore, there exists significant challenges to this endeavour and tapping into this precise physical relationship needs further work and further direction.

An excellent starting point of the ways in which we should conceive of how the physical relationship between affect and emotion plays out upon and through the corporeal can be seen 
in the detailed account of the emotive by Sara Ahmed (2003, 2004). She consistently emphasises the relation between emotions and the body, which complements my efforts to both highlight emotion as the physical (re)performance of affect and trace this interplay. However, while I argue that emotion gains a physicality from the affective, Ahmed contends that emotion is this physicality and collapses affect into emotion. Despite this discrepancy between theoretical terrains, Ahmed still facilitates a nuanced, broad, and detailed analysis of the emotive that should direct our engagement with these registers. Recognising the centrality of the corporeal to the emotive, she positions emotion as 'the feeling of bodily change' (Ahmed 2004, 5), enabling a (re)focus upon the tangible capabilities of emotion. Her scrutiny of the experience of pain is conveyed as the 'recognition of a sensation...involves the reconstitution of bodily space, as the reorientation of the bodily relation to that which gets attributes as the cause of pain' (Ahmed 2004, 24). Through the example of hate, Ahmed $(2004,49)$ asserts that emotion involves the 'spatial reorganisation of bodies through the very gestures of moving away from others that are felt to be the "cause" of our hate.' Again, in her discussion of fear, Ahmed $(2004,8)$ demonstrates the tangible effects that emotion elicits in the corporeal and points to the physical characteristics of the emotive as 'fear shapes the surface of bodies in relation to objects.' From this crucial work, then, it becomes evident that we need to (re)orientate a focus on the corporeal, on bodies that are reacting to, reconstituting, and reattributing affect and emotion.

There clearly exists, across disciplines, both a desire and impetus to open up new ways of looking at and understanding the registers of affect and emotion and their relation to the corporeal. As already outlined, Critical Security Studies has embraced these concepts of affect and emotion and represents a fertile ground for both the development and utilisation of these registers. However, what is missing from these analyses is how affect and emotion will always supersede control and, as such, how bodies through these registers can disrupt and 
rupture attempts at governance at spaces of (in)security. Therefore, the focus so far has been on lines of control that are dependent on affect and emotion. Now, I argue, we need to refocus on layers of control and disruption, layers of obedience and deviance, and layers of cohesion and dissonance - all which speak of the complexity and liveliness of affect and emotion. Yet, in order to formulate a succinct picture or imaginary of these two registers, the dependence upon the physical - to trace obedience and deviance - within this relationship necessitates the creation of a framework to infer affect. To address the theoretical endeavour of the physical potential of affect into the actualised expression of emotion, via the body, warrants a guide or recipe to identify the transformations and translations of affect in fieldwork and research.

\section{How to Infer Affect: Liminal Sites}

Putting this theoretical framework of the relation between affect and emotion into action, then, warrants approaching 'the research process differently based on our theoretical questioning... [and] that this too should inflect our presentational practices' (Adey et al 2013, 308). The intervention that I want to make in this article and the guiding principle that I want to foreground is that when looking for affect and emotion, we need to imagine and experience our fieldwork and/or research as liminal sites. Firstly, what constitutes these sites, covers a broad range; denoting physical space, visuals or images and photographs, bodies deemed (in)secure, or anywhere that we seek to identify the influence of affect and emotion.

Secondly, the use of the liminal, as derived from Van Gennep's (1960) conception, represents a frontier or a precipice. Although often seen as bewildering due to the 'transitory' and 'betwixt' nature (Pritchard and Morgan 2006, 764), the liminal is highly useful as there is an inherent movement and progression within the liminal from the 'known to the unknown' 
(Nisbet 1969, 4). This foregrounding of transition within the liminal inspires the impetus to re-think and re-conceptualise these sites. So, approaching affect and emotion becomes less about deducing or presupposing a clear narrative and seeking that out, and more about encountering fieldwork or research (whether physical space, text, imagery etc.) as sites for reorientation and transformation. Thus, the applicability of the analogy of fieldwork and research as liminal sites is that the liminal represents the potential to resist and contest 'dominant discourses [and] wider hegemonic social-cultural relations' (Pritchard and Morgan 2006, 762). As Ward $(2012,185)$ considers, the liminal space is one of 'testing' where 'landscapes and people have been placed beyond the boundaries of their "home" culture's ordering system, and which present challenges to the...prior sense of identity.' As such, this should guide how we seek to encounter affect and emotion. Not as given, decided or (pre)determined but as always fluid, testing, and unknown; in other words, our encounters with affect and emotion should always be open to interpretation.

Thus, due to the uncontrollable nature of affect and emotion, our fieldwork and research ought to be comfortable with trying to (re)present a place to be disorientated, if not actively seeking disorientation. Within these liminal sites, we should wade through the multiple layers of potential, perceived, and real affects and emotions without clinging onto linear narratives or dominant perceptions of how these two registers ought to unfold. The liminal is then a useful analogy to hold in mind as we "do" our research so that we do not become overwhelmed by these lively registers but rather appreciate their plurality, and the complexity and depth that it will give to our understandings of affect and emotion. Of course, some sort of guiding framework or approach is needed in order to deconstruct these liminal sites and to articulate a way to deal with the entanglements of affect, emotion, and the corporeal as they intertwine further throughout diverse sites. At this point, then, I argue that we need to think through the liminal sites of fieldwork or research in layers, not lines. 


\section{Layers not Lines}

Encountering fieldwork or research through layers, allows for different experiences, affects, emotions, and dispositions to come to the fore. Taken together, these layers aim to present a sort of framework in order to embark upon the process of deciphering the liminal sites of research and fieldwork that are always already changing, ambiguous, and open to interpretation. Therefore, the layers are about submerging ourselves within, and embracing, the messy entanglements of researching affect and emotion and their potential as liminal to disrupt, metamorphose, and disorientate/re-orientate.

\section{Layer One: A Point of Orientation}

The first layer that I suggest to encounter what we should see as liminal sites provides a starting point to the researcher. Importantly, what is offered is not an anchor to colour the encountered affects and emotion, but instead a point of orientation in order to understand what bodies ought to be feeling, experiencing, and acting out. Layer one is about uncovering and revealing genealogies and dominant discourses that rely on certain manipulated and engineered affects and emotions to create the ideal or amenable body type - whether to distract from insecurities or to secure against threats and potential vulnerability.

By engaging with genealogies, what is uncovered are the 'local memories which allow us to establish a historical knowledge of struggles and to make use of this knowledge tactically today' (Foucault 1980, 83). Genealogies are telling of the ways in which specific and favourable temporalities that are employed in space, literary representations and "official" histories (among many other examples) are inherently reliant on affect and emotion. As such, within the liminal sites that we search for affect and emotion, genealogies help to pinpoint the 
elements of these registers that are enhanced, favoured, and presented as inherent and essentialised to paint a favourable image that bodies ought to absorb and conform to. Thus, the affects and emotions that bodies are acting out or that they may encounter, through genealogies, can be seen as a result of a series of decisions and foreclosures, rather than from any natural and benign narrative.

For example, in my own research in New York City, tracing genealogies became the starting point for understanding how sites have historically constituted the "ideal" identity for both the bodies occupying space and the actual space itself. At Grand Central Terminal (GCT), the operationalisation of nostalgia has been widely adopted in order to suppress the discourse of (in)security that haunts sites of transportation (O' Hanlon, et al. 2003; Wilson, et al. 2007). The emotion of nostalgia has been suggested as a potent way to manage feelings of terror (Routledge, et al. 2008) and as a positive emotion that 'alleviates existential threat' (Sedikides, et al. 2008, 304). The purpose of nostalgia, then, is to focus people's attention on a preferred time or era of the Terminal. The current threat of terrorism and (in)security, and the measures that are used to secure the space, are based on imagined futures, assumptions of what may happen and algorithims that try to counteract a (possible) future, here in the present (Anderson 2010; Aradau and van Munster 2012). Whereas nostlagia is used to direct interpretations of the space back to a time when the concerted effort of the Terminal was not to secure bodies against terrorism, but to make them feel in awe of a beautfiul site and feat of architecture. This idea of nostalgia being used to fracture temporalities comes from the recognition that 'nostalgia feels stifled with conventional confines of time' (Boym 2001, xiv) and that this emotion 'undermines linear notions of progress' (Huyssen 2006, 7). What nostalgia is being relied upon to do in this first layer, then, is to dirupt the presentism of terrorism and security measures that are operating in the space in order to look back upon the past. Importantly, nostalgia is not about revealing a "true" and "factual" re-telling of the past, 
it is 'not supposed to reveal any signs of decay; it has to be freshly painted... and remain eternally young' (Boym 2001, 49). Thus, genealogies do not have to be accurate or singular, indeed they can skip through time and gloss over insecurities and, in so doing this, can bring an idealised past to fruition in the present to subsume and counteract fears for the future that the threat of (in)security invokes.

However, linking back to the idea of layers rather than lines, genealogies are not static and should not be over-determined. So, while nostalgia appears to me as the dominant desired emotion at Grand Central Terminal, this is not to negate that I, equally, am a body that can be swayed by affect and emotion. In the same vein, my understanding of how GCT sells itself as a tourist site, rather than a transit hub, is not a determined fact but simply a point of orientation that emerges from my own interaction with the space. As a result, what it is possible for bodies to feel and the affects that it is possible, or even just encouraged, to act out, are all dependent on this history or genealogy of these very same affects and emotions. They are the frames of reference that are manipulated in order to create a favourable and cohesive narrative that bodies can tap into and ought to easily replicate the associated affects and emotions. Within this layer, then, we need to collect materials that are related to our sites in order to understand the ways in which bodies are being encouraged to act and perform. As potential examples, in space, we can use maps to look at where bodies are being ushered, the artwork that is encouraging certain feelings, and the dominant and preferred identity that is presented.

What genealogy is doing for the researcher, is allowing us to see the affects and emotions that have been locked in place, made to seem essential, but, ironically, the sites are inherently dependent on bodies to act them out for the coherence and continuity of the site. In the 
example of Grand Central Terminal, what became seen as natural were bodies gazing, awestruck, lost in wonder, and distracted from (in)security. The merit of genealogies is that they show how what is presented as history or as official, rather than being an objective representation of the site, is actually a political act that favours and privileges certain affects, emotions, and bodies. Therefore, layer one and the site materials that are used to reveal genealogies and dominant discourses are a point of orientation to understand the types of affects, emotions, and bodies that are being privileged and foregrounded as natural or essential to the site. Importantly, though, these representations of the sites, and the registers and bodies being favoured, are not anchors, but simply highlight what the different sites think you ought to be attuned to. As, at every site, there will exist lines where certain bodies $d o$ conform directly to the affects and emotions of this genealogy. The work of layer two, then, is to enable us to move on from this and look for the diversity that interrupts and punctures this first layer.

\section{Layer Two: A Point of Departure and Disorientation}

As layer one, through genealogical review, facilitates the recognition of the affects, emotions, and bodies (and their dispositions) that would be classified as desired or obedient, then layer two becomes focused on discovering those registers and dispositions that would be categorised as deviant or aberrant, and, therefore, silenced. As such, layer two represents a point of departure, what is in opposition to the point(s) of orientation? Where is the deviance? Of equal importance to sketching out the relationship between affect and emotion across fieldwork and research, is to try and determine the affects that are not being encouraged, the emotions being silenced, and the bodies that are (made) absent. Searching for the elements of these registers that are "missing," in this layer, becomes about listening to silence and 
actively seeking out deviance, difference, and discomfort. Treating our sites as liminal, where 'usual practice and order are suspended' (Czarniawska and Mazza 2003, 267), we need to recognise disruptive moments as simply another range of active affects and emotions that add to the liveliness and plurality of the site.

Firstly, to step away from those affects, emotions, and bodies that are privileged in layer one, we need to be conscious of the position of our own body and the attendant registers and dispositions that we carry with us. For example, my reaction to, and interpretation of, different sites and mechanisms of (in)security is inherently coloured by my personal experience of being young, white, and female (Foss and Foss 1994: Jokinen and Caretta 2016). By attuning ourselves to the affects and emotions that are (un)expected of our own bodies, we can then start to think through and envision the multiplicities of registers and of bodies that are interruptive at these sites.

From this, in terms of method, I argue that tapping into the physicality of affect, is inherently linked to ethnography through the focus that must be given to the corporeal. For layer two, the basis for the methodological framework is formed by engaging in 'thick description' (Geertz 1973, 5) of the affects, emotions, and bodies that are constituted by and constitutive of our fieldwork or research. Usefully, ethnography has been central in the existing debates regarding method, specifically in Critical Security Studies (Salter and Mutlu 2013: Stump 2017), as it enables us to be sensible to bodies within the security context. Thus, ethnography in this layer, enables a 'human-centred approach' that presents 'opportunities to access and understand experiences and narratives' (Johnson 2014, 362) that are often silenced or erased by dominant accounts (Ratelle 2013). From this, we are subsequently able to address the diversity of affect and emotion, and attempt to uncover alternative examples of these registers that are often hidden or effaced in our sites. This can be done by asking, to start, what can bodies be seen to be doing? In space, are they circulating or are they loitering? In 
photographs, are bodies relaxed and at ease, or are they tense and poised? Through sculptures and artwork, are our bodies interrupted, stopped or slowed down, or mobilised? In effect, are bodies being orientated in line with layer one or are they telling a story of disorientation?

To use my example, again, of Grand Central Terminal, the first affective and emotive layer of the site speaks of nostalgia operating to distract from fears of (in)security. In line with this, bodies would be expected to be in awe, wondrous, and captivated by the space. Yet, when spaces, specifically tourist sites, do not match certain preconceived expectations, people can easily become disillusioned and disorientated (Del Casino and Hanna 2000). So, instead of being enthralled by the space, the disorientated bodies (those that cannot or do not tap into the points of orientation) may sit on the stairs of the Main Concourse utterly bored or flick through their phone looking glum. At Grand Central Terminal, then, the bored, uninterested, and uncertain body disrupts and punctures the discourse of nostalgia that is meant to distract people from feeling (in)security and from feeling threatened. Of course, it may be that these people feel so comfortable and at ease in the space that they are willing to ignore their surroundings. Nevertheless, these are certainly not expressions of the awe and wonder that you are supposed to feel at GCT. As such, the affects that these bodies perform and the emotions that they experience, all upset and trouble the manipulation of nostalgia within the Terminal. In reaction, their deviance becomes the locus against which security is enacted and they are the bodies that must be moved along from sitting on the stairs at the Main Concourse due to "health and safety reasons."

A more blatant example, though, of the translation of a threat narrative onto bodies that are not directly in-line with the desired affects and emotions is the treatment of the homeless body at this space. Although the exclusion and vilification of homeless people is, unfortunately, a common feature of public spaces (Amster 2003; May 2014), it is clear that the absolute poverty of these bodies deviates totally from the desired nostalgic affects and 
emotions at GCT. In effect, the homeless were the strangers that Ahmed speaks of as 'those who are not known in this dwelling, but those who are, in their very proximity, already recognised as not belonging, as being out of place' (Ahmed 2010, 21). Subsequently, what I found was, in reaction to this unsettling of the preferred emotion, the homeless identity became a proxy for the "threat" at GCT, and the presence of these people became legislated against and they were forcibly removed from the Terminal. As such, points of disorientation can be found in those bodies that are not following or cannot follow the prescribed affects and emotions and, moreover, can be traced through the bodies that have security enacted and mobilised against them. Therefore, in this layer, we need to not only question what bodies are doing, but also, which bodies are security practices being enacted against? As, this will lead us to the political and cultural scripts (often gendered, racist, and classist) that are both reliant on and interrupted by affect and emotion.

\section{Layer Three: Re-orientating Points}

Finally, the third layer of inferring affect, is concerned with re-orientation. If we merge the previous two layers to formulate an understanding of the registers and dispositions that are privileged and those that are silenced, we can start to pull out potential interpretations of these sites. Importantly, the aim is not to establish one, set, and determined representation of affect, emotion, and the corporeal, but to pick apart the political importance of potential interpretations of these sites. Just as emotion is one potential expression of the physicality of affect, as are the inferences garnered through these sites. The layers remain representative of the uncontrollability, unpredictability and eruptive nature of affect, but still allow for the emergence of potential interpretations of the sites. Thus, we are seeking to embrace 
ambiguity and disruption in order to be able to re-orientate the dominant representations within these liminal sites.

Ultimately, these layers will always be unstable but we can validate our interpretations through triangulation. This move to triangulation is not to create a complete understanding of the affective and emotive landscape of these sites, but to manage and hold together the layers of multiplicities, obedience, fractures, and dissonance. Taking all of these layers together and the insights that they offer, it is essential to triangulate and validate the observations and physical clues with a vast array of academic literature to substantiate the conclusions being drawn. Essentially, this stage is about corroborating and supporting the (re)orientations of affect, emotion, and the corporeal that have been uncovered through the three layers, as just one potential expression. This validation can be achieved through building upon existing work in academia that relates, as just a few examples, affect and emotion to different spatial configurations and architecture (Kraftl and Adey 2008), uses of colour (Anderson, Vuori and Guillaume 2015), art (Amoore and Hall 2010), celebrity endorsement (Nunn and Biressi 2010) and the natural world (Milstein 2009). The merging of the two layers with the third layer of existing academic scholarship, then, functions to support the interpretations formed but, importantly, does not seek to shut down alternative analyses or readings.

\section{Challenges}

It is important to note that while the idea of layers provides some semblance of guidance through the multiplicities of affects, emotions, and bodies, this approach to method still engenders implicit challenges itself. Although contentious whether a challenge or a benefit of this method, the fact remains that these layers result in a huge amount of material gathered observations, photographs, site histories, artwork, documentaries, newspaper articles, and 
many others. The subsequent triangulation of all of these materials with the genealogies of layer one, with disorientation noted in layer two, and academic scholarship in layer three, often leads to an overwhelming and juxtaposing jumble of results. While an aim of the triangulation of affect is to show that affect and emotion are always diverse, multiple, and plural, there is still a need to draw out intelligible representations of these registers. At this point of the merging, cross-correlation, and ultimate triangulation of all of this information, the idea of 'mess' (Law 2004) in social sciences, broadly, and methodologies specifically, helps to deal with the complexity, diversity, and, often, contradictory nature of the conclusions reached. By imagining all of these diverse representations as 'allegory,' it becomes possible to 'hold together' a multitude of results that do not 'necessarily cohere' (Law 2004, 90). The use of these layers and of embracing the liminal, slots into methodological debates that are less about 'desirable order, fixity, or closure' and more about exploring and locating 'moments of movement and flux alongside those attempts to contain, simplify or tame those dynamics' (Jarvis 2009,4 ). In this way, both the collection and presentation of analyses and conclusions that are sought through these layers answers methodological calls that seek to make space for 'ambivalence and ambiguity,' as 'realities made manifest do not necessarily have to fit together' (Law 2004, 90).

Finally, there is also the initial challenge (if not irony) that I outlined, of translating affect something that is pre-linguistic and troubles our attempts to capture it - onto a page. Not only do we have to describe affect, emotion, and the corporeal in a legible way, but we also have to do this whilst simultaneously foregrounding their physicality. From this, then, the importance of the use of site materials throughout the three layers helps to deal with this paradox. By (re)presenting our interpretations of the sites in tandem with physical evidence of maps, drawings, photographs, videos, sketches of the flows of bodies, samples of materials (and many others), we can start to transpose the physical onto a page. Although not perfect, 
these layers and the materials within them, are about 'rejuvenating method' (Lisle 2014) in order to deal with the physicality of affect, emotion, and the corporeal.

\section{Conclusion}

In all, this article is inherently linked to the study of security, both in terms of centralising the power of affect and emotion, and also through the diversification of our methodological terrain (Aradau et al 2014, Salter and Mutlu 2013). As such, what this article has offered is both new ways to think around these registers, and how they can be understood and examined as simultaneously obedient and deviant to structures of power, such as security practices and mechanisms.

Moving forward, with both this theoretical and methodological framework, the implications for our study of security are to complement existing work on the ways in which affect and emotion are increasing relied upon to order bodies and how we can now trace and uncover the interruptions to, and the reworking of, these power structures. Through imagining and engaging with fieldwork and research as liminal sites, I have shown how we can ultimately re-orientate our understandings of these sites and destabilise dominance which is supposed, sustained, and (re)performed through affect, emotion, and the corporeal. Opening ourselves up to the disorientation of the liminal then prepares us for the ambiguity and troubling of affect. From this, rather than being overwhelmed by all of the eruptive, and lively affects, emotions, and bodies at these sites, we can hold together and juggle these pluralities through thinking in terms of layers. Furthermore, by accepting that the information gathered from these layers only offer one interpretation of the sites, this approach to method allows us to reflect the unpredictability of affect. As such, the "physical story" that is generated across 
these sites, will never be the same as that of another timeframe, another researcher, or another body generally, such is the nature of affect and emotion.

\section{References}

Adey, P, L Brayer, D Masson, P Murphy, P Simpson, and N Tixier. 2013. "'Pour Votre Tranquillité': Ambiance, Atmosphere and Surveillance.” Geoforum 49299 - 309.

Adey, Peter. 2008. "Airports, Mobility and the Calculative Architecture of Affective Control." Geoforum 39 (1) 438 - 451.

Adey, Peter. 2009. "Facing Airport Security: Affect, Biopolitics, and the Preemptive Securitisation of the Mobile Body." Environment and Planning D: Society and Space Vol. 27274 - 295.

Åhäll, Linda. 2018. "Affect as Methodology: Feminism and the Politics of Emotion.” International Political Sociology Vol. 12 No. 136 - 52.

Åhäll, Linda, and Thomas A Gregory. 2013. "Security, Emotions, Affect." Critical Studies on Security Vol. 1 No. 1117 - 120.

Ahmed, Sara. 2004. The Cultural Politics of Emotion. Edinburgh: Edinburgh University Press.

Ahmed, Sara. 2003. "The Politics of Fear in the Making of Worlds." International Journal of Qualitative Studies in Education Vol. 16 No. 3377 - 398.

Ahmed, Sara. 2000. “Strange Encounters Embodied Others in Post-Coloniality. ” Oxford: Routledge.

Amoore, Louise. 2006. "Biometric borders: Governing Mobilities in the War on Terror." Political Geography Vol. 25 No. 3336 - 351. 
Amoore, Louise, and Alexandra Hall. 2010. "Border Theatre: On the Arts of Security and Resistance.” Cultural Geographies Vol. 17 No. 3299 - 319.

Amoore, Louise, and Alexandra Hall. 2009. "Taking People Apart: Digitised Dissection and the Body at the Border.” Environment and Planning D: Society and Space Vol. 27444 $-464$.

Amster, R. 2003. "Patterns of Exclusion: Sanitizing Space, Criminalizing Homelessness." Social Justice 30195 - 221.

Anderson, Ben. 2010. "Preemption, Precaution, Preparedness: Anticipatory Action and Future Geographies.” Progress in Human Geography 34 (6) 777 - 798.

Anderson, Ben, and Peter Adey. 2011. "Affect and Security: Exercising Emergency in 'UK Civil Contingencies'.” Environment and Planning D: Society and Space Vol. 291092 $-1109$.

Anderson, Rune S, Juha A Vuori, and Xavier Guillaume. 2015. "Chromatology of Security: Introducing Colours to Visual Security Studies.” Security Dialogue Vol. 46(5) 440 457.

Aradau, Claudia, and Rens van Munster. 2012. "The Time/Space of Preparedness: Anticipating the "Next Terrorist Attack"." Space and Culture Vol. 15 No. 298 - 109.

Aradau, Claudia, Jef Huysmans, Andrew Neal, and Nadine Voelkner. 2014. Critical Security Methods: New Frameworks for Analysis. New York: Routledge.

Bissell, D, M Hynes, and S Sharpe. 2012. "Unveiling Seductions Beyond Societies of Control: Affect, Security, and Humour in Spaces of Aeromobility." Environment and Planning D: Society and Space 30694 - 710. 
Bleiker, Roland, and Emma Hutchinson. 2008. "Fear No More: Emotions and World Politics." Review of International Studies 34115 - 135.

Boym, Svetlana. 2001. The Future of Nostalgia. New York : Basic Books.

Butler, Judith. 1989. "Foucault and the Paradox of Bodily Inscriptions." The Journal of Philosophy Vol LXXXVI No 11601 - 607.

—. 1990. Gender Trouble. London: Routledge.

Closs Stephens, Angharad. 2016. "The Affective Atmospheres of Nationalism." Cultural Geographies Vol. 23 No. 2181 - 198.

Clough, P T. 2010. “The Affective Turn: Political Economy, Biomedia, and Bodies.” In The Affect Theory Reader, by M Gregg and G J Seigworth, 206 - 225. Durham: Duke University Press.

Clough, P T, and J Halley. 2007. The Affective Turn: Theorising the Social. London: Duke University Press.

Czarniawska, Barbara, and Carmelo Mazza. 2003. "Consulting as a Liminal Space.” Human Relations Vol. 56 No. 3267 - 290.

Del Casino, Vincent J, and Stephen P Hanna. 2000. "Representations and Identities in Tourism Map Spaces.” Progress in Human Geography 24:1 23 - 46.

Deleuze, G. 1988. Spinoza: Practical Philosophy translated by R. Hurley. San Francisco: City Lights.

Deleuze, Gilles. 1997. Essays Critical and Clinical, trans. D. W. Smith and M. A. Greco. Minneapolis: University of Minnesota Press. 
Foss, K A, and S K Foss. 1994. "Personal Experience as Evidence in Feminist Scholarship." Western Journal of Communication (includes Communication Reports) Vol. 58 No. 1 $39-43$.

Foucault, Michel. 1980. “Two Lectures.” In Power/Knowledge: Selected Interviews and Other Writings 1972 - 1977, by Colin Gordon, 78 - 109. New York: Pantheon Books.

Geertz, C. 1973. The Interpretation of Cultures. New York: Basic Books.

Grosz, Elizabeth A. 1994. Volatile Bodies: Toward a Corporeal Feminism. Indiana: Indiana University Press.

Heath-Kelly, Charlotte, and Lee Jarvis. 2017. “Affecting Terrorism: Laughter, Lamentation, and Detestation as Drives to Terrorism Knowledge.” International Political Sociology $11239-256$.

Hutchinson, Emma. 2013. "Affective Communities as Security Communities.” Critical Studies on Security Vol. 1 No. 1127 - 129.

Hutchinson, Emma, and Roland Bleiker. 2014. "Theorizing Emotions in World Politics ." International Theory Vol. 6 No. 3491 - 514.

Huyssen, Andreas. 2006. "Nostalgia for Ruins.” Grey Room No. 23 Spring 6 - 21.

Innes, Alexandria J. 2017. "Everyday Ontological Security: Emotion and Migration in British Soaps.” International Political Sociology 11380 - 397.

James, William. 1884. "What is an Emotion?” Mind Vol 9 No. 34188 - 205.

Jarvis, Lee. 2009a. Times of Terror: Discourse Temporality and the War on Terror. New York: Palgrave Macmillan. 
Johnson, Heather L. 2014. "Ethnographic Translations: Bringing together Multi-Sited Studies." Critical Studies on Security Vol 2 No 3362 - 365.

Jokinen, J C, and M A Caretta. 2016. "When Bodies do not Fit: An Analysis of Postgraduate Fieldwork." Gender, Place and Culture 1 - 12.

Kraftl, Peter, and Peter Adey. 2008. “Architecture/Affect/Inhabitation: Geographies of Being-In Buildings.” Annals of the Association of American Geographers Vol. 98 No. $1213-231$.

Law, John. 2004. After Method: Mess in Social Science Research. New York: Routledge.

Lisle, Debbie. 2014. "Rejuvenating Method.” Critical Studies on Security Vol. 2 No. 3370 373.

Lorimer, H. 2008. "Cultural Geography: Non-Representational Conditions and Concerns." Progress in Human Geography 32551 - 559.

Lutz, Catherine A, and Lila Abu-Lughod. 1990. Studies in Emotion and Social Interaction. Language and the Politics of Emotion. Cambridge : Cambridge University Press.

Massumi, Brian. 2002. Parables for the Virtual: Movement, Affect, Sensation. London: Duke University Press.

Massumi, Brian. 1995. "The Autonomy of Affect.” Cultural Critique No. 31 The Politics of Systems and Environments Part II Autumn 83 - 109.

May, Jon. 2014. "Modes of Attentiveness: Reading for Difference in Geographies of Homelessness.” Antipode Vol. 14 No. 4894 - 920.

Milstein, Tema. 2009. “'Somethin' Tells Me It's All Happening at the Zoo': Discourse, Power and Conservationism.” Environmental Communication Vol. 3 No. 125 - 48. 
Negri, Antonio. 1999. "Value and Affect.” Boundary 2 Vol. 26 No. 277 - 87.

Ngai, Sianne. 2002. ""A Foul Lump Started Making Promises in my Voice": Race, Affect, and the Animated Subject." American Literature Vol. 74 No. 3571 - 601.

Nisbet, R A. 1969. Social Change and History: Aspects of the Western Theory of Development. London: Oxford University Press.

Nunn, Heather, and Anita Biressi. 2010. “'A Trust Betrayed:' Celebrity and the Work of Emotion." Celebrity Studies Vol. 1 No. 149 - 64.

Nussbaum, Martha C. 2001. Upheavals of Thought: The Intelligence of Emotions. Cambridge: Cambridge University Press.

O' Hanlon, M E, Peter Orszag, Ivo H Daalder, Destler I M, David L Gunter, James M Lindsay, Robert E Litan, and James B Steinberg. 2003. Protecting the American Homeland: One Year On. Washington D.C.: Brookings Institution.

Pritchard, Annette, and Nigel Morgan. 2006. "Hotel Babylon? Exploring Hotels as Liminal Sites of Transition and Transgression.” Tourism Management Vol. 27762 - 772.

Ratelle, J. 2013. "How Participant Observation Contributes to the Study of (in)security Practices in Conflict Zones." In Research Methods in Critical Security Studies: An Introduction, by Mark B Salter and Can E Mutlu, 76 - 79. New York: Routledge.

Routledge, Clay, Jamie Arndt, Constantine Sedikides, and Tim Wildschut. 2008. “A Blast from the Past: The Terror Management Function of Nostalgia." Journal of Experimental Social Psychology Vol. 44132 - 140.

Salter, Mark B. 2007. "Governmentalities of an Airport: Heterotopia and Confession." International Political Sociology 149 - 66. 
—. 2008. Politics at the Airport. London: University of Minnesota Press.

Salter, Mark B. 2012. "Theory of the / : The Suture and Critical Border Studies." Geopolitics Vol. 17 No. 4734 - 755.

Salter, Mark B, and Can E Mutlu. 2012. "Psychoanalytic Theory and Border Security." European Journal of Social Theory Vol. 15 No. 2179 - 195.

—. 2013. Research Methods in Critical Security Studies: An Introduction. New York: Routledge.

Sedikides, C, T Wildschut, J Arndt, and C Routledge. 2008. "Nostalgia: Past, Present and Future.” Current Directions in Psychological Science Vol. 17304 - 307.

Spinoza, Baruch. 1985. "Ethics.” In Complete Works, by Edwin Curley. New Jersey: Princeton University Press.

Stump, Jacob L. 2017. "What's the Use of Fieldwork with an Ethnographic Sensibility for Security Studies?” Critical Studies on Security Vol. 5 No. 2192 - 193.

Thompson, S, and P Hoggett. 2012. Politics and the Emotions. London: Continuum.

Thrift, Nigel. 2004. "Intensities of Feeling: Towards a Spatial Politics of Affect." Geografiska Annaler. Series B. Human Geography, Vol. 86 No. 157 - 78.

Van Gennep, A. 1960. The Rites of Passage. Chicago: University of Chicago Press.

Van Ramshorst, Jared P. 2017. "Laughing About It: Emotional and Affective Spaces of Humour in the Geopolitics of Migration.” Geopolitics 1 - 20.

Ward, Simon. 2012. “'Danger Zones': The British 'Road Movie' and the Liminal Landscape.” In Liminal Landscapes: Travel, Experience and Spaces In-Between, by Hazel Andrews and Les Roberts, 185 - 199. Oxford: Routledge. 
Wetherell, Margaret. 2012. Affect and Emotion: A New Social Science Understanding. London: Sage.

Wilson, Jeremy M, Brian A Jackson, Mel Eisman, Paul Steinberg, and Jack Riely. 2007. Securing America's Passenger Rail System. Santa Monica: Rand Corporation. 